\title{
Antimicrobial Susceptibility and Multilocus Sequence Typing of Listeria monocytogenes Isolated Over 11 Years from Food, Humans, and the Environment in Italy
}

\author{
Marta Caruso,, Rosa Fraccalvieri,, Frédérique Pasquali, ${ }^{2}$ Gianfranco Santagada, Laura M. Latorre, \\ Laura M. Difato,' Angela Miccolupo, Giovanni Normanno, ${ }^{3}$ and Antonio Parisi ${ }^{1}$
}

\begin{abstract}
Due to the increasing number of studies reporting the detection of antimicrobial-resistant isolates of Listeria monocytogenes, we sought to determine the antimicrobial susceptibility of L. monocytogenes isolates collected in Italy and find potential correlations to their serotypes and multilocus sequence types (MLST). The antimicrobial susceptibility of 317 L. monocytogenes isolates collected from food, humans, and the environment from 1998 to 2009 was assessed by minimum inhibitory concentration (MIC). Serotyping and MLST was also performed on all isolates. Potential correlations among antimicrobial resistance profiles, serotyping, and MLST were statistically evaluated. Twenty-four percent of L. monocytogenes isolates were resistant to oxacillin, $28.7 \%$ intermediate to clindamycin, and $24.3 \%$ to ciprofloxacin. The majority of isolates with elevated MIC to oxacillin was of environmental origin and belonged to serotype $4 \mathrm{~b} / 4 \mathrm{e}$ and ST2. Isolates with intermediate MIC values to clindamycin and ciprofloxacin were mostly of food and human origin and belonged to serotype $4 \mathrm{~b} / 4 \mathrm{e}$ and ST9. Regarding the time frame of isolate collection, comparing the last 3 years (2007-2009) to previous years (1998-2006), an increase was observed in the percentage of resistant and intermediate isolates per year. This trend strongly suggests the need for increasing attention on the prevalence of antimicrobial resistance in L. monocytogenes in Italy. To predict future resistance trends, the monitoring of clinical intermediate resistance might represent a useful tool especially for antibiotics associated to multiple-step mechanisms of acquired resistance. A specific focus should be addressed to antimicrobial-resistant isolates of serotype $4 \mathrm{~b}$, repeatedly associated with food-borne outbreaks.
\end{abstract}

Keywords: Listeria monocytogenes, antimicrobial susceptibility, serotyping, multilocus sequence typing

\section{Introduction}

N THE PAST DECADES, Listeria monocytogenes has been implicated in several outbreaks of food-borne illness in humans with a statistically significant increasing trend of listeriosis since 2008 (Schlech et al., 1983; EFSA and ECDC, 2015). While it has been established that food-borne transmission constitutes the main acquisition route of listeriosis (Farber and Peterkin, 1991; Swaminathan and Gerner-Smidt, 2007), most healthy humans are not significantly affected by the intake of small numbers of L. monocytogenes in foods (Pouillot et al., 2015). However, the risk of developing clinical listeriosis is higher for people with existing chronic illness, suppression of the immune system, pregnancy, or extreme youth or older age (younger than the age of 1 year or older than 60 years) (Swaminathan and Gerner-Smidt, 2007). For these vulnerable persons, the mortality rate remains high ( 16\%) (Scallan et al., 2011). Patients affected by listeriosis are usually treated with aminopenicillin or benzylpenicillin in conjunction with an aminoglycoside. Vulnerable and immunocompromised patients at risk of listeriosis might follow an empiric treatment with broad spectrum antibiotics such as piperacillin/tazobactam or carbapenems (Thønnings et al., 2016)

Listeria spp. has been generally reported susceptible to almost all antimicrobials, except for cephalosporins, fosfomycin, and macrolides, against which Listeria spp. has been described as naturally resistant or with reduced susceptibility (Charpentier and Courvalin, 1999; Troxler et al., 2000). However, reports of L. monocytogenes resistant to a wide

\footnotetext{
${ }^{1}$ Istituto Zooprofilattico Sperimentale della Puglia e della Basilicata, Foggia, Italy.

${ }^{2}$ Department of Agricultural and Food Sciences, Alma Mater Studiorum-University of Bologna, Bologna, Italy.

${ }^{3}$ Facoltà di Agraria, Università degli Studi di Foggia, Foggia, Italy.
} 


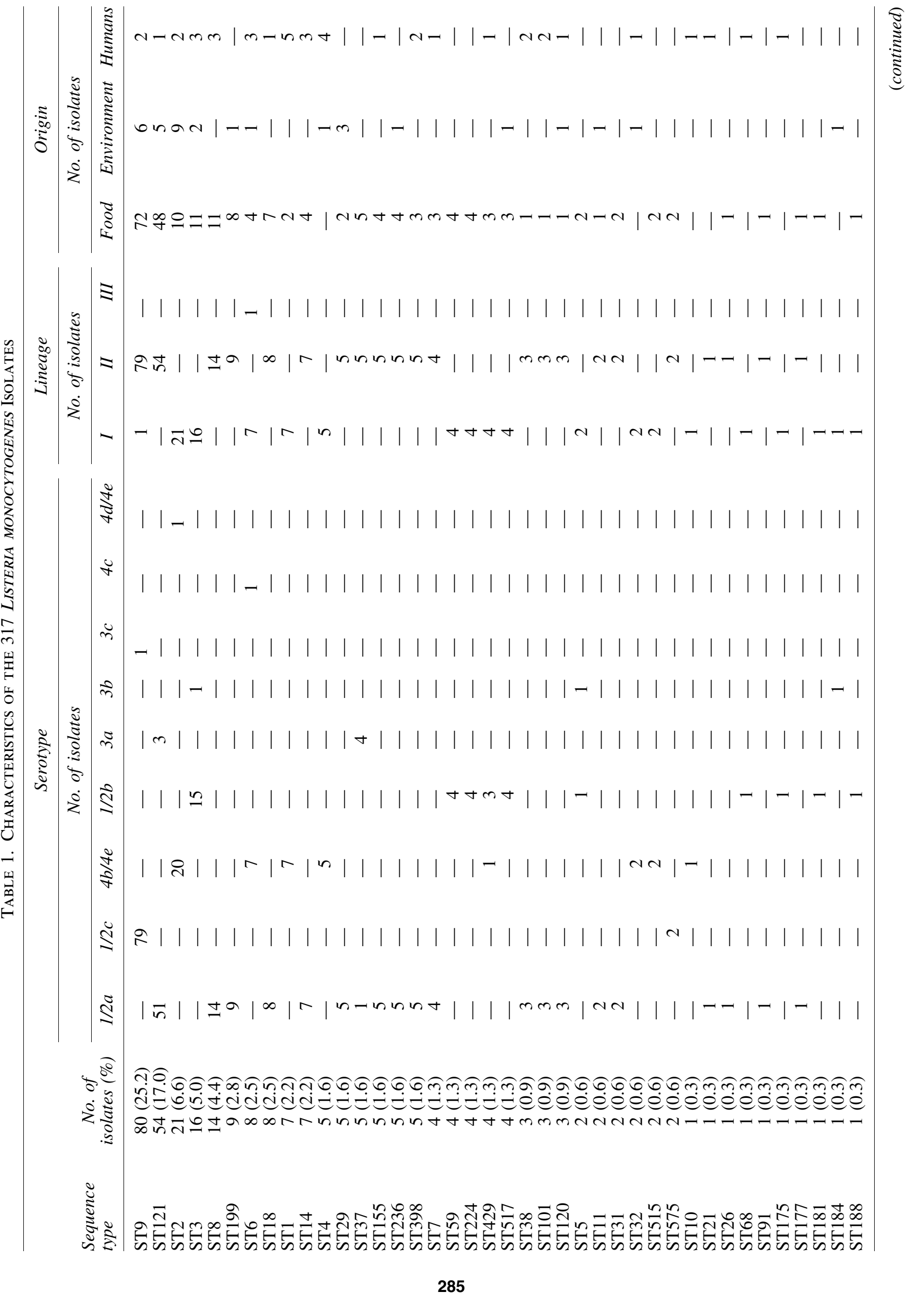




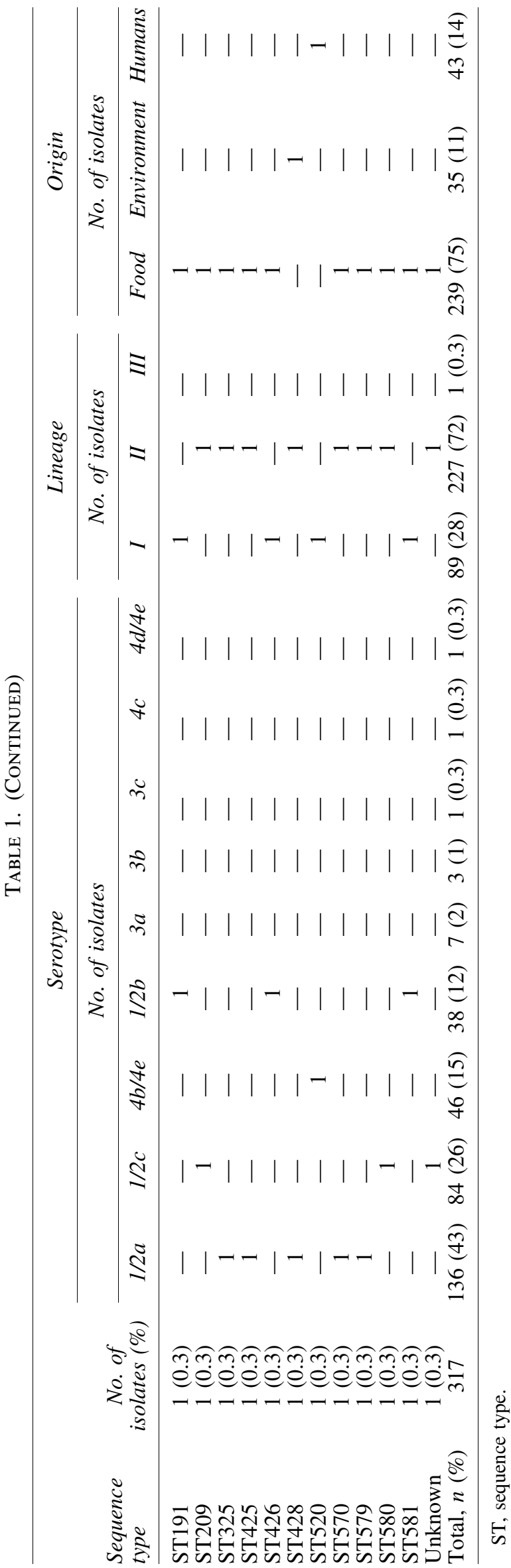

range of antimicrobial agents have been published. Since the first report of a multiresistant clinical isolate in France in 1988, antimicrobial-resistant isolates collected from humans, food, plants, and the environment have been described worldwide (Charpentier et al., 1995; Srinivansan et al., 2005; Granier et al., 2011; Ruiz-Bolivar et al., 2011; Bertsch et al., 2014; Moreno et al., 2014; de Vasconcelos Byrne et al., 2016; and Li et al., 2016). In humans, resistance of $L$. monocytogenes against tetracycline and ciprofloxacin has been described (Morvan et al., 2010). In food, high prevalence of oxacillin and clindamycin resistance was described recently among isolates from meat and fish production chains (Walsh et al., 2001; Lyon et al., 2008; Chen et al., 2010; Gómez et al., 2014). Similarly, significant percentages of resistance against ampicillin, penicillin $\mathrm{G}$, and tetracycline were reported in L. monocytogenes isolated from meat, fish, and dairy production chains (Aras and Ardıç, 2015; Jamali et al., 2015; Kevenk and Gulel, 2016).

The emergence and spread of antimicrobial-resistant Listeria spp. has been attributed to the overuse of antibiotics in disease treatments and growth promotion in domestic livestock (Charpentier et al., 1995; Walsh et al., 2001).

In the present study, the antimicrobial susceptibility of 317 L. monocytogenes isolates collected in a 11-year period (1998-2009) from humans, food, and environmental surfaces was assessed along with serotype and multilocus sequence type (MLST) to: (1) evaluate the occurrence of antimicrobial resistance and intermediate resistance in $L$. monocytogenes over time; (2) correlate antimicrobial resistance phenotype with origin, serotype, and sequence type.

\section{Materials and Methods}

\section{L. monocytogenes isolates}

A total of 317 L. monocytogenes isolates recovered between 1998 and 2009 from food $(n=239$, including 162 meat products, 38 dairy products, 17 seafood, 22 ready-to-eat products), humans $(n=43)$, and environment $(n=35$, including 17 food-processing environment, 6 animal feces, 4 soil, 4 water, and 4 plants) were analyzed in this study.

All the isolates were previously identified using confirmation tests: Gram stain, mobility at $25^{\circ} \mathrm{C}$ in motility agar, catalase test, oxidase test, fermentation of xylose and rhamnose, hemolysis test on sheep blood agar plates, CAMP test against Staphylococcus aureus and Rhodococcus equi, and the API Listeria ${ }^{\circledR}$ (BioMérieux, Marcy l'Etoile, France).

\section{Serotyping}

Serotyping was carried out using commercial specific antisera (Denka Seiken, Tokyo, Japan) against the serovars 1/ $2 \mathrm{a}, 1 / 2 \mathrm{~b}, 1 / 2 \mathrm{c}, 3 \mathrm{a}, 3 \mathrm{~b}, 3 \mathrm{c}, 4 \mathrm{c}, 4 \mathrm{~d} / 4 \mathrm{e}$, and $4 \mathrm{~b} / 4 \mathrm{e}$, following the manufacturer's instructions (Ueda et al., 2002).

\section{Multilocus sequence typing}

Genomic DNA was extracted using GenomicPrep ${ }^{\circledR}$ cell and tissue isolation kit (Amersham, Piscataway, NJ) following the manufacturer's instructions. DNA concentrations were determined at a wavelength of $260 \mathrm{~nm}$ using the spectrophotometer DU640 (Beckman, Fullerton, CA). The final concentration of DNA was adjusted to $10 \mathrm{ng} / \mathrm{mL}$ with RNAse, DNAse, and Protease-free water (Sigma-Aldrich, Milan, Italy). 
Seven DNA sequences belonging to the $a b c Z, b g l A, c a t$, $d a p E, d a t, l d h$, and $l h k A$ genes were amplified by polymerase chain reaction (PCR) and sequenced. All genes were amplified using previously published primers (Salcedo et al., 2003), except for the $l d h$ gene, for which the primers suggested from a modified MLST scheme (www.pasteur.fr/mlst) were used (Ragon et al., 2008). PCRs were carried out in $25 \mu \mathrm{L}$ reaction volumes containing $10 \mathrm{pmol}$ of each primer, $0.2 \mathrm{mM}$ of each dNTP's, $1 \mathrm{U}$ HotMaster Taq (Eppendorf, Milan, Italy), and $2.5 \mathrm{~mL}$ of $10 \mathrm{X}$ HotMaster Taq Buffer (Eppendorf). The reaction conditions were an initial denaturation at $94^{\circ} \mathrm{C}$ for $2 \mathrm{~min}$, followed by 25 cycles at $94^{\circ} \mathrm{C}$ for $30 \mathrm{~s}, 52^{\circ} \mathrm{C}$ for $30 \mathrm{~s}$, and $72^{\circ} \mathrm{C}$ for $1 \mathrm{~min}$. The PCR products were purified using Montage ${ }^{\circledR}$ PCR filter units (Millipore, Milan, Italy). Sequence reactions were carried out using BigDye 3.1 Ready Reaction Mix (Thermo Fisher Scientific, Milan, Italy) according to the manufacturer's instructions. The sequenced products were separated with a 3130 Genetic Analyzer (Thermo Fisher Scientific). Sequences were imported and assembled with the BioNumerics 7.1 software (Applied Maths, Belgium). Alleles and sequence type (ST) were assigned by submitting the DNA sequences to the Listeria MLST database at the Pasteur Institute in France (www.pasteur.fr/mlst). A unweighted pair group method with arithmetic mean (UPGMA) tree was built using MLST profiles of the selected isolates using BioNumerics 7.6 software (Applied Maths). The visualization and the annotation of the phylogenetic tree were performed using the web-based tool Interactive Tree of Life. Strains were grouped into clonal complexes, defined as groups of profiles differing by no more than one gene from at least one other profile of the group (Feil, 2004).

\section{Antimicrobial susceptibility testing}

Isolates were subjected to minimum inhibitory concentration (MIC) using Sensititre ${ }^{\circledR}$ plates GPN4F and GPALL1F (Trek Diagnostic Systems, Cleveland, $\mathrm{OH}$ ) specific for Grampositive bacteria and including a wide variety of antibiotics at a full range of MIC: erythromycin $(0.25-4 \mu \mathrm{g} / \mathrm{mL})$, clindamycin $(0.5-2 \mu \mathrm{g} / \mathrm{mL})$, quinupristin/dalfopristin $(0.5-4 \mu \mathrm{g} / \mathrm{mL})$, streptomycin $(1000 \mu \mathrm{g} / \mathrm{mL})$, vancomycin $(1-32 \mu \mathrm{g} / \mathrm{mL})$, tetracycline $(2-16 \mu \mathrm{g} / \mathrm{mL})$ ampicillin $(0.12-8 \mu \mathrm{g} / \mathrm{mL})$, gentamycin $(2-16 \mu \mathrm{g} / \mathrm{mL})$, rifampin $(0.5-4 \mu \mathrm{g} / \mathrm{mL})$, trimetho$\mathrm{prim} /$ sulfamethoxazole $(0.5 / 9.5-4 / 76 \mu \mathrm{g} / \mathrm{mL})$, chloramphenicol $(2-16 \mu \mathrm{g} / \mathrm{mL})$, oxacillin $+2 \% \mathrm{NaCl}(0.25-8 \mu \mathrm{g} / \mathrm{mL})$, penicillin $\mathrm{G}(0.06-8 \mu \mathrm{g} / \mathrm{mL})$, and ciprofloxacin $(1-2 \mu \mathrm{g} / \mathrm{mL})$. The MIC against L. monocytogenes isolates was assessed following the broth microdilution method reported in Clinical and Laboratory Standards Institute (CLSI) M45-A3 document accordingly CLSI breakpoints were used for MIC categorization (CLSI, 2016). In brief, isolated colonies were suspended in sterile demineralized water to achieve a 0.5 McFarland. From the bacterial suspension, $10 \mu \mathrm{L}$ were transferred to $90 \mu \mathrm{L}$ Mueller-Hinton Broth with lysed horse blood (Trek Diagnostic Systems) and inoculated onto the MIC plates, which were incubated $24 \mathrm{~h}$ at $35^{\circ} \mathrm{C}$. MIC values were manually recorded. Escherichia coli ATCC 25922 and Enterococcus faecalis ATCC 29212 were used as quality control strains. Each experiment was performed in duplicate.

As CLSI breakpoints for L. monocytogenes only include ampicillin, penicillin, and trimethoprim/sulfamethoxazole, and L. monocytogenes belongs to the Bacillales order, CLSI breakpoints for Bacillus were used for the following antimicrobials: erythromycin, clindamycin, vancomycin, tetracycline, gentamicin, rifampin, chloramphenicol, and ciprofloxacin (document CLSI M45-A3) (CLSI, 2016; Yan et al., 2016). CLSI breakpoints for Staphylococci, Enterococci, and Corynebacteri were used for oxacillin, streptomycin, and quinupristin/dalfopristin, respectively (CLSI M45-A3, CLSI VET01-S2) (CLSI, 2013, 2016).

\section{Statistical analysis}

Chi-square test was performed using StatView 5.0 software (SAS 155 Institute Inc., USA) to compare nominal variables between serotypes, lineages, and sequence types.

\section{Results}

\section{Serotype, lineage, sequence type}

Serotyping of the 317 L. monocytogenes strains identified the following serotypes: $1 / 2 \mathrm{a}(43 \% ; n=136), 1 / 2 \mathrm{c}(26 \%$; $n=84), 4 \mathrm{~b} / 4 \mathrm{e}(15 \% ; n=46), 1 / 2 \mathrm{~b}(12 \% ; n=38), 3 \mathrm{a}(2 \%$; $n=7), 3 \mathrm{~b}(1 \% ; n=3), 3 \mathrm{c}, 4 \mathrm{c}$, and $4 \mathrm{~d} / 4 \mathrm{e}(0.32 \% ; n=1)$.

In the population of $L$. monocytogenes, there are three lineages: the lineage I includes isolates of serotype $4 b / 4 e, 1 /$ $2 \mathrm{~b}, 3 \mathrm{~b}, 4 \mathrm{~d} / 4 \mathrm{e}$, and $3 \mathrm{c}$, the lineage II isolates of serotype $1 / 2 \mathrm{a}$, $1 / 2 \mathrm{c}$, and $3 \mathrm{a}$, and the lineage III isolates of serotype $4 \mathrm{a}$ and $4 \mathrm{c}$. Of the 317 strains, $72 \%$ (227/317) belonged to the lineage II, $28 \%(89 / 317)$ to the lineage I, and $0.31 \%(1 / 317)$ to the lineage III.

MLST analysis of the 317 strains identified 52 different sequence types. The most representative STs were ST9 $(25 \%$; $n=80)$, ST121 (17\%; $n=54)$, ST2 (7\%; $n=21)$, ST3 (5\%; $n=16)$, and ST8 (4\%; $n=14)$. The results of MLST analysis, serotyping and Lineage distribution of the 317 isolates, and their source are summarized in Table 1.

\section{Antimicrobial susceptibility}

The MIC distribution of the 317 isolates is reported in Table 2. Using the breakpoints given, all isolates were susceptible to erythromycin, streptomycin, vancomycin, ampicillin, gentamicin, rifampin, trimethoprim/sulfamethoxazole, chloramphenicol, and penicillin. From all isolates tested, $54 \%(170 / 317)$ were intermediate or resistant to certain antimicrobials. In detail, of the 317 isolates tested, 91 (29\%) were intermediate to clindamycin, 77 (24\%) to ciprofloxacin, and $2(1 \%)$ to quinupristin/dalfopristin; $76(24 \%)$ were resistant to oxacillin, 4 (1\%) to tetracycline, and $2(1 \%)$ to ciprofloxacin. Among all intermediate or resistant isolates, $59 \%(101 / 170)$ were intermediate or resistant to only one antimicrobial, $33 \%(56 / 170)$ to two antimicrobials, and $8 \%$ (13/170) to three antimicrobials (Table 3).

In relationship to the origin, the percentage of oxacillinresistant isolates was significantly higher in the environment in comparison to food and humans $(46 \%, 19 \%$, and $35 \%$, respectively) $(p<0.05)$ (Table 4$)$, while the percentages of both clindamycin and ciprofloxacin intermediate strains were significantly higher in human isolates in comparison to food and the environment $(60 \%, 23 \%$, and $29 \%$, respectively, for clindamycin intermediate isolates and $70 \%, 19 \%$, and $3 \%$, respectively, for ciprofloxacin intermediate isolates) $(p<0.001)$ (Table 4). 
Table 2. Minimum Inhibitory Concentration Distribution of the 317 Listeria monocytogenes Strains

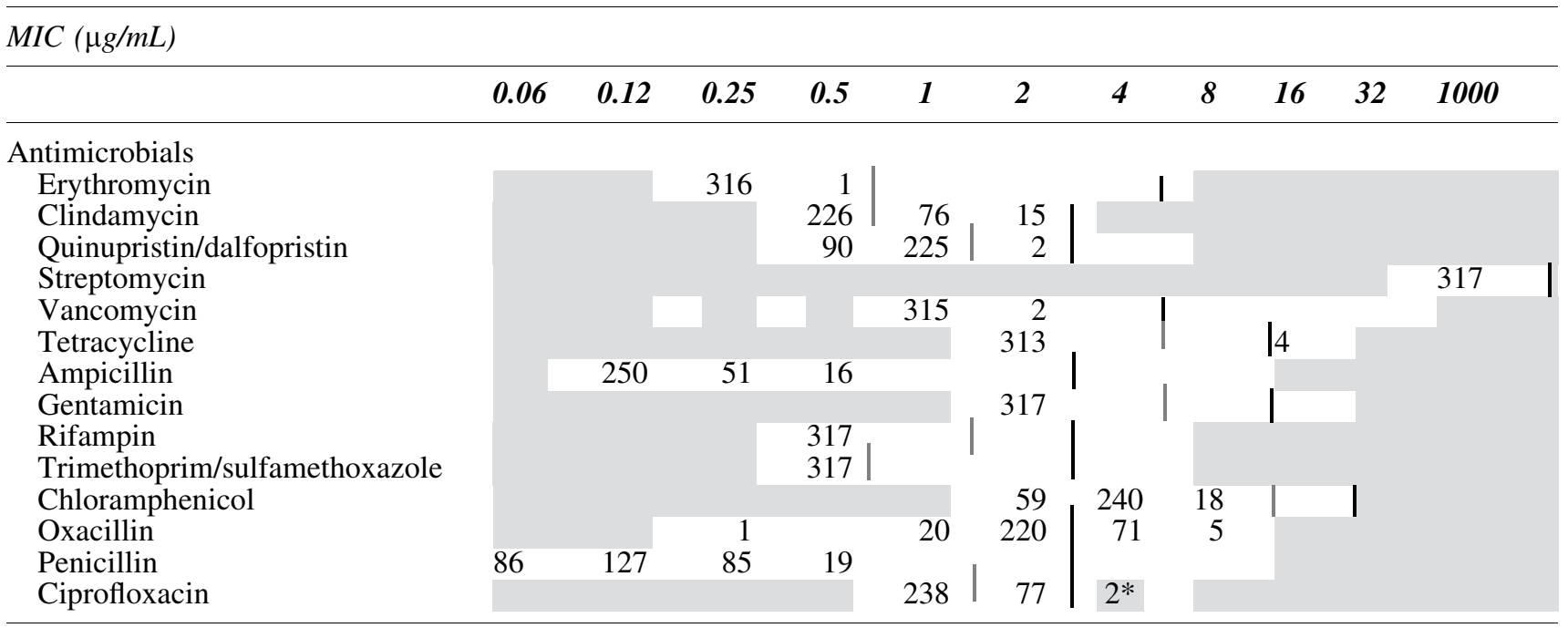

| Black vertical lines indicate breakpoints for resistance.|Gray vertical lines indicate breakpoints for intermediate. Gray shading indicates that the isolates were not tested for susceptibility to those concentrations of a given antimicrobial agent. Asterisked number indicates the number of isolates exhibiting MIC values equal to or higher than concentration of the test range.

MIC, minimum inhibitory concentration.

In relationship to the lineage, the percentage of oxacillinresistant strains was significantly higher in isolates of lineage I $(58 / 89 ; 65 \%)$ compared with lineage II $(18 / 227 ; 8 \%)$ $(p<0.001)$ (Table 5) (Fig. 1). No significant differences were found between the percentages of clindamycin and ciprofloxacin intermediate strains belonging to the two lineages (Fig. 1) (Table 5).

In relationship to the serotype, the percentages of oxacillinresistant as well as clindamycin and ciprofloxacin intermediate strains were significantly higher in isolates of serotype $4 \mathrm{~b} / 4 \mathrm{e}$ $(72 \%, 35 \%$, and $33 \%$, respectively) $(p<0.05)$ (Table 6$)$.

Isolates were collected in a broad time period ranging from 1998 to 2009. Comparing the last 3 years (2007-2009) to previous years (1998-2006), a clear positive trend of increase was observed in the percentage of resistant and intermediate

Table 3. Antimicrobial Resistance Patterns OF Listeria MONOCYTOGENES STRAINS

\begin{tabular}{lc}
\hline Resistance patterns & No. of isolates \\
\hline OXA & 45 \\
CLI & 35 \\
CIP & 20 \\
TET & 1 \\
CLI-CIP & 35 \\
CLI-CIP & 1 \\
OXA-CIP & 10 \\
OXA-CIP & 1 \\
CLI-OXA & 7 \\
OXA-TET & 1 \\
TET-CIP & 1 \\
CLI-OXA-CIP & 10 \\
CLI-SYN-OXA & 2 \\
CLI-TET-CIP & 1 \\
TOTAL & 170 \\
\hline
\end{tabular}

Underlined names represent intermediate susceptibility.

CIP, ciprofloxacin; CLI, clindamycin; OXA, oxacillin; SYN, quinupristin/dalfopristin; TET, tetracycline. isolates per year. In particular, the percentage of oxacillinresistant and clindamycin intermediate strains increased from $22 \%$ to $28 \%$ and from $26 \%$ to $35 \%$, respectively, and the percentage of ciprofloxacin intermediate strains increased from $21 \%$ to $34 \%$ (Table 7). The increase was statistically significant only for ciprofloxacin intermediate strains $(p<0.05)$.

\section{Discussion}

The Listeria genus was described as susceptible to antibiotics active against Gram-positive bacteria, including ampicillin or penicillin (combined with aminoglycosides), trimethoprim (alone or combined with sulfamethoxazole), tetracyclines, erythromycin, and gentamicin (Rota et al., 1996; Teuber, 1999; Yücel et al., 2005). High susceptibility of isolates to ampicillin (100\%), penicillin (100\%), tetracyclines (99\%), gentamicin (100\%), erythromycin (100\%), and trimethoprim-sulfamethoxazole $(100 \%)$ were observed in the present study (Table 1). Similar results were also previously reported (Conter et al., 2009; Yan et al., 2010; Barbosa et al., 2013; Wang et al., 2013; Madeo et al., 2015).

Few isolates showed resistance to tetracycline (4/317; $1.3 \%)$ and ciprofloxacin $(2 / 317 ; 0.6 \%)$, whereas a consistent number of isolates showed resistance to oxacillin and intermediate resistance to clindamycin or ciprofloxacin $(24 \%$, $28.7 \%$, and $24.3 \%$, respectively). Also, intermediate resistance to quinupristin/dalfopristin was observed in $2(0.6 \%)$ L. monocytogenes isolated from water and plant (environmental source).

In our study, resistance to oxacillin was $24 \%$ for L. monocytogenes isolated from selected sources. Oxacillin resistance has been already associated to L. monocytogenes with even higher percentages in research studies from Brazil, United States, and Poland (Davis and Jackson, 2009; Wieczorek et al., 2012; Camargo et al., 2015). In Staphylococcus infections, oxacillin susceptibility test is used as a marker for methicillin-resistant Staphylococcus aureus. This resistance is associated with the mecA gene coding for an alternative 

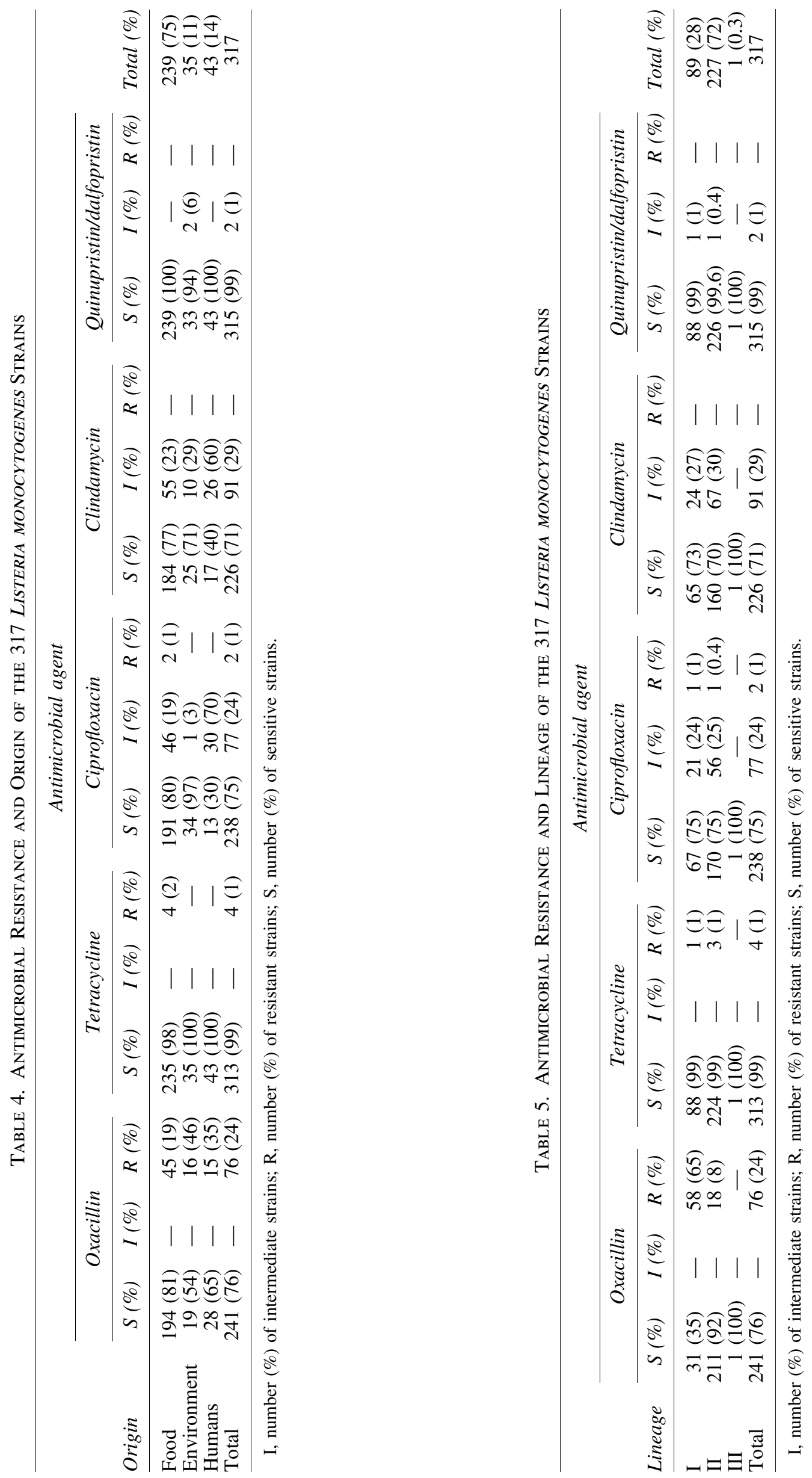


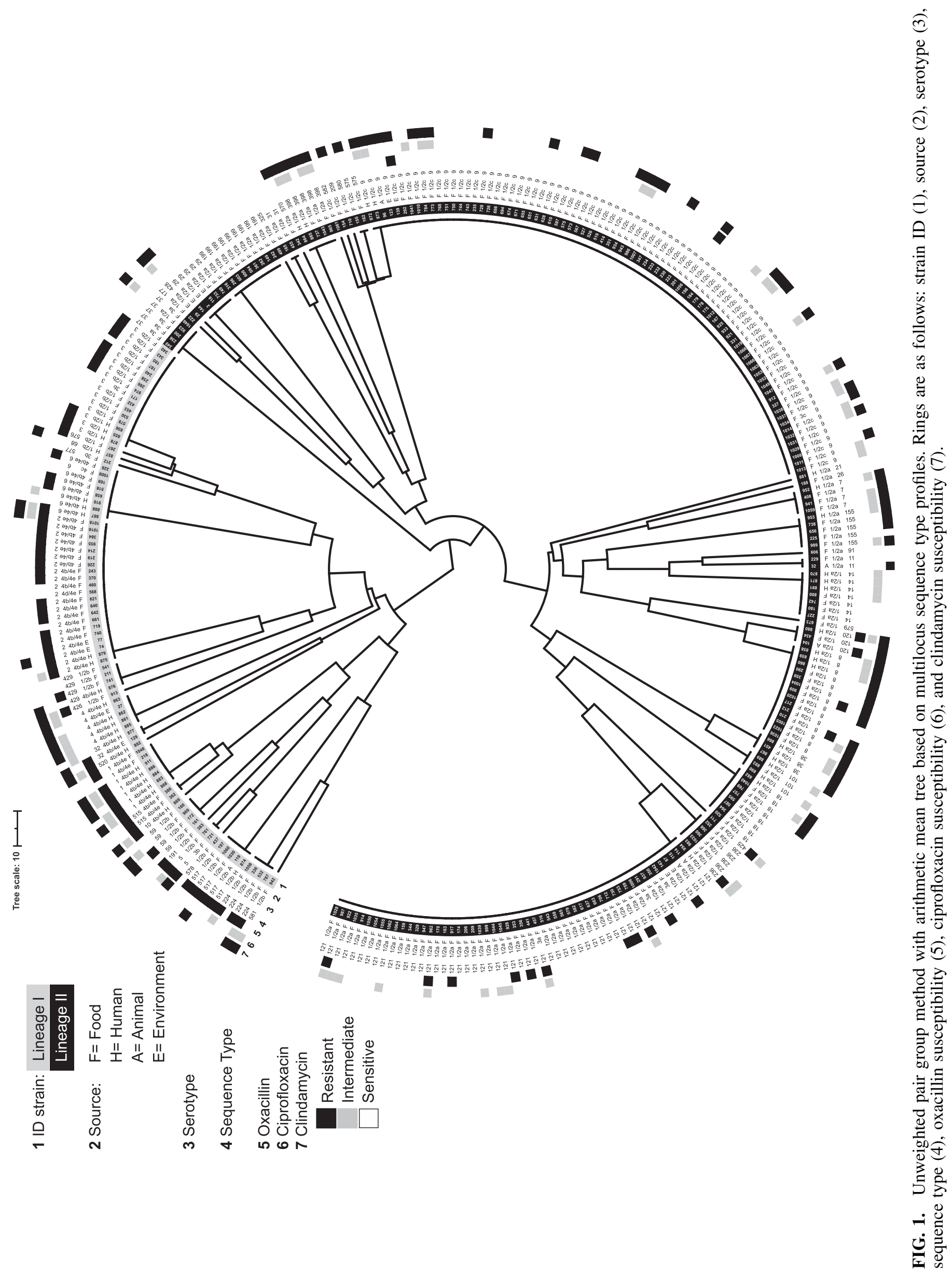




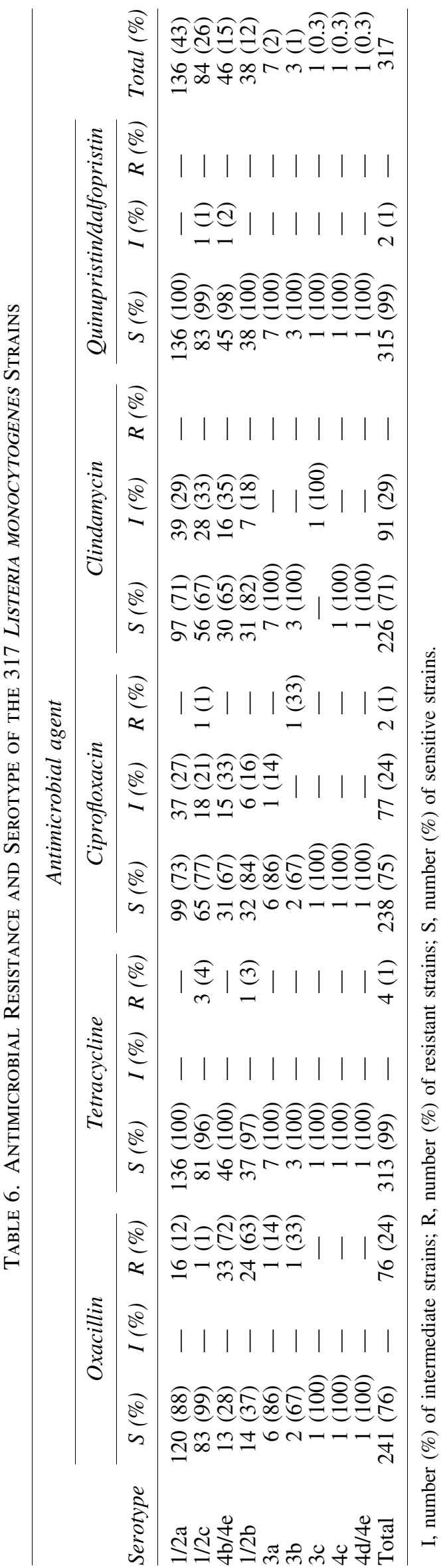

penicillin-binding protein namely PBP2A with low-binding affinity to $\beta$-lactam antibiotics (Reichmann and Pinho, 2017). Further studies need to be performed to verify whether similar molecular mechanisms of oxacillin resistance are true also for Listeria.

In the present study $>20 \%$ of $L$. monocytogenes isolates showed intermediate MIC values for clindamycin and ciprofloxacin. These intermediate values are particularly interesting. Acquired resistance to both antimicrobials is a multistep process linked to the subsequent acquisition of multiple point mutations in core genes. In particular, clindamycin resistance was associated with methylation and mutations in the $23 \mathrm{~S}$ rRNA (Kehrenberg et al., 2005; Poehlsgaard et al., 2005; Kulczycka-Mierzejewska et al., 2018). Ciprofloxacin resistance was associated to mutations in the quinolone resistance determining region of $g y r A$, overexpression of efflux pump gene llde and mutation in the fepR gene, and regulator of the efflux pump protein gene fepA in L. monocytogenes (Lampidis et al., 2002; Godreuil et al., 2003; Moreno et al., 2014; Jiang et al., 2018; Wilson et al., 2018).

Intermediate MIC values suggest a probable future shift to resistance phenotypes in case of acquisition of additional mutations. Significant percentages of clindamycin and ciprofloxacin resistance have been already described worldwide (Davis and Jackson, 2009; Wieczorek et al., 2012; Camargo et al., 2015; Noll et al., 2017).

An interesting statistical correlation has been found between resistance and lineages/serotypes. In particular, oxacillin resistance was significantly more frequently identified in lineage I and in particular in serotype $4 \mathrm{~b} / 4 \mathrm{e}$. Similarly, the percentages of isolates with intermediate clindamycin or ciprofloxacin MIC values were significantly higher in serotype $4 \mathrm{~b} / 4 \mathrm{e}$. A correlation between some L. monocytogenes serotypes and antimicrobial resistance has been previously reported although no explanation for these observations has been proposed yet. For instance, Barbosa et al. (2013) found that resistance to erythromycin was correlated with the serotype $4 \mathrm{~b}$, whereas no correlation was observed between ciprofloxacin resistance and $L$. monocytogenes serotypes (Safdar and Armstrong, 2003). On the contrary, other authors found that serotype $1 / 2 \mathrm{a}$ isolates were more frequently resistant to ciprofloxacin compared to serotype $4 \mathrm{~b}$ (Safdar and Armstrong, 2003; Kovacevic et al., 2013). Besides, the association of antimicrobial resistance or reduced susceptibility to serotype $4 \mathrm{~b}$ is of concern, since strains belonging to this serotype were associated to outbreaks (Althaus et al., 2017; Buchanan et al., 2017; Burall et al., 2017).

The two most frequently identified STs among intermediate and resistant isolates to clindamycin, ciprofloxacin, and oxacillin were ST9 and ST2, respectively. These two STs have been found in different food categories. The high level of exposure might be the reason of the high contribution to listeriosis cases of these STs (Henri et al., 2016).

Along with single antimicrobial resistance or reduced susceptibility, $8 \%$ of resistant isolates showed resistance to three or more antimicrobials and therefore fall within the definition of multidrug-resistant isolates (Table 3) (Magiorakos et al., 2012). Results from other studies reported multidrug resistance in L. monocytogenes isolated from food and animals to chloramphenicol, erythromycin, gentamicin, kanamycin, streptomycin, and rifampin (Charpentier et al., 1995; Walsh et al., 2001; Srinivasan et al., 2005). However, 
Table 7. Antimicrobial Resistance of the 317 Listeria monocytogenes Strains Over Time

\begin{tabular}{|c|c|c|c|c|c|c|c|c|c|c|}
\hline \multirow[b]{2}{*}{ Time period } & \multicolumn{3}{|c|}{ Oxacillin } & \multicolumn{3}{|c|}{ Clindamycin } & \multicolumn{3}{|c|}{ Ciprofloxacin } & \multirow[b]{2}{*}{ Total } \\
\hline & $S(\%)$ & $I(\%)$ & $R(\%)$ & $S(\%)$ & $I(\%)$ & $R(\%)$ & $S(\%)$ & $I(\%)$ & $R(\%)$ & \\
\hline 1998-2006 & 177 (78) & - & $51(22)$ & $168(74)$ & $60(26)$ & - & $180(79)$ & $47(21)$ & $1(0.4)$ & 228 \\
\hline $2007-2009$ & $64(72)$ & - & $25(28)$ & $58(65)$ & $31(35)$ & - & $58(65)$ & $30(34)$ & $1(1)$ & 89 \\
\hline
\end{tabular}

I, number (\%) of intermediate strains; R, number (\%) of resistant strains; S, number (\%) of sensitive strains.

Godreuil et al. (2003) reported that only five of 488 clinical isolates of L. monocytogenes were susceptible to chloramphenicol and vancomycin (Walsh et al., 2001).

Although L. monocytogenes was noted to be relatively susceptible to a wide range of antimicrobials as few as 20 years ago, a number of more recent reports suggests that the rate of antimicrobial resistance in L. monocytogenes is increasing from $1 \%$ to $10 \%$ up to $50 \%$ (Vela et al., 2001; Walsh et al., 2001; Godreuil et al., 2003; Barbosa et al., 2013; Gómez et al., 2014; Thønnings et al., 2016; Arslan et al., 2019). Accordingly, in the present study, a median increase per year of the percentage of antimicrobial resistant or reduced susceptible isolates to oxacillin, clindamycin, and ciprofloxacin was observed in the period 2007-2009 in comparison to previous years (1998-2006). These results are consistent to a previous Italian study based on a large antimicrobial susceptibility survey conducted in 1995. In this study, all 148 isolates were susceptible to $\beta$-lactams, lincosamides, and tetracycline (Aureli et al., 2003). Conversely, in a more recent study performed in France on 4816 clinical $L$. monocytogenes strains isolated between 1926 and 2007, although low, resistance to specific antimicrobials (tetracyclines and fluoroquinolones) was found to be emerging (Morvan et al., 2010).

In France, a 10-year period study, mostly overlapping the years in the present work (1996-2006) isolated only 4 resistant isolates among the 202 food and environmental samples analyzed (Granier et al., 2011). This is in contrast with the observation of the present study, in which 170 isolates were identified resistant over 317 isolates analyzed. Although it must be said that in the present dataset, isolates of human origin were also included, their relative few number (43) does not significantly bias the comparison.

In comparison to previous studies, results suggest significant different trends of antimicrobial-resistant L. monocytogenes from food and the environment in European neighboring countries in the first decade of the century. In addition, in line with the concept of epidemiological cutoff values, evaluation of clinical intermediate resistance in L. monocytogenes might represent a useful tool to predict future occurrence of resistant strains against antibiotics associated with a multistep acquisition mechanism. If confirmed on additional L. monocytogenes isolates collected in more recent years, the Italian increase of resistant and intermediate L. monocytogenes isolates to oxacillin, clindamycin, and ciprofloxacin is a matter of concern. This observation is particularly relevant especially in case of antimicrobial-resistant isolates of serotype $4 \mathrm{~b}$, which is repeatedly associated with food-borne outbreaks.

\section{Disclosure Statement}

No competing financial interests exist.

\section{Funding Information}

This work was supported by the Italian Ministry of Health (RC IZSPB 05/08).

\section{References}

Althaus D, Jermini M, Giannini P, Martinetti G, Reinholz D, Nüesch-Inderbinen M, Lehner A, Stephan R. Local outbreak of Listeria monocytogenes serotype 4b sequence type 6 due to contaminated meat pâté. Foodborne Pathog Dis 2017;14:219_ 222.

Aras Z, Ardiç M. Occurrence and antibiotic susceptibility of Listeria species in turkey meats. Korean J Food Sci Anim Resour 2015;35:669-673.

Arslan S, Baytur S. Prevalence and antimicrobial resistance of Listeria species and subtyping and virulence factors of Listeria monocytogenes from retail meat. J Food Safety 2019;39: e12578.

Aureli P, Ferrini AM, Mannoni V, Hodzic S, WedellWeergaard C, Oliva B. Susceptibility of Listeria monocytogenes isolated from food in Italy to antibiotics. Int J Food Microbiol 2003;83:325-330.

Barbosa J, Magalhães R, Santos I, Ferreira V, Brandão TR, Silva J, Almeida G, Teixeira P. Evaluation of antibiotic resistance patterns of food and clinical Listeria monocytogenes isolates in Portugal. Foodborne Pathog Dis 2013;10:861-866.

Bertsch D, Muelli M, Weller M, Uruty A, Lacroix C, Meile L. Antimicrobial susceptibility and antibiotic resistance gene transfer analysis of foodborne, clinical, and environmental Listeria spp. isolates including Listeria monocytogenes. Microbiologyopen 2014;3:118-127.

Buchanan RL, Gorris LGM, Hayman MM, Jackson TC, Whiting RC. A review of Listeria monocytogenes: An update on outbreaks, virulence, dose-response, ecology, and risk assessments. Food Control 2017;75:1-13.

Burall LS, Grim CJ, Datta AR. A clade of Listeria monocytogenes serotype $4 \mathrm{~b}$ variant strains linked to recent listeriosis outbreaks associated with produce from a defined geographic region in the US. PLoS One 2017;12:pii: e0176912.

Camargo AC, de Castilho NP, da Silva DA, Vallim DC, Hofer E, Nero LA. Antibiotic Resistance of Listeria monocytogenes isolated from meat-processing environments, beef products, and clinical cases in Brazil. Microb Drug Res 2015;21:458462.

Charpentier E, Courvalin P. Antibiotic resistance in Listeria spp. Antimicrob Agents Chemother 1999;43:2103-2108.

Charpentier E, Gerbaud G, Jacquet C, Rocourt J, Courvalin P. Incidence of antibiotic resistance in Listeria species. J Infect Dis 1995;172:277-281.

Chen BY, Pyla R, Kim TJ, Silva JL, Jung YS. Antibiotic resistance in Listeria species isolated from catfish fillets and processing environment. Lett Appl Microbiol 2010;50:626632. 
CLSI. Methods for Antimicrobial Dilution and Disk Susceptibility Testing for Bacteria Isolated from Animals: Second Informational Supplement VET01-S2. Wayne, PA: CLSI, 2013.

CLSI. Methods for Antimicrobial Dilution and Disk Susceptibility Testing of Infrequently Isolated or Fastidious BacteriaThird Edition: Approved Standard M45-A3. Wayne, PA: CLSI, 2016.

Conter M, Paludi D, Zanardi E, Ghidini S, Vergara A, Ianieri A. Characterization of antimicrobial resistance of foodborne Listeria monocytogenes. Int J Food Microbiol 2009;128:497500.

Davis A, Jackson JRC. Comparative antimicrobial susceptibility of Listeria monocytogenes, L. innocua, and L. welshimeri. Microb Drug Res 2009;15:27-32.

de Vasconcelos Byrne V, Hofer E, Vallim DC, de Castro Almeida RC. Occurrence and antimicrobial resistance patterns of Listeria monocytogenes isolated from vegetables. Braz $\mathrm{J}$ Microbiol 2016;47:438-443.

EFSA (European Food Safety Authority) and ECDC (European Centre for Disease Prevention and Control). The European Union summary report on trends and sources of zoonoses, zoonotic agents and food-borne outbreaks in 2014. EFSA J 2015;13:4329.

Farber JM, Peterkin PI. Listeria monocytogenes, a food-borne pathogen. Microbiol Rev 1991;55:476-511.

Feil J. Small change: Keeping pace with microevolution. Nat Rev Microbiol 2004;2:483-495.

Godreuil S, Galimand M, Gerbaud G, Jacquet C, Courvalin P. Efflux pump Lde is associated with fluoroquinolone resistance in Listeria monocytogenes. Antimicrob Agents Chemother 2003;47:704-708.

Gómez D, Azón E, Marco N, Carramiñana JJ, Rota C, Ariño A, Yangüela J. Antimicrobial resistance of Listeria monocytogenes and Listeria innocua from meat products and meatprocessing environment. Food Microbiol 2014;42:61-65.

Granier SA, Moubareck C, Colaneri C, Lemire A, Roussel S, Dao TT, Courvalin P, Brisabois A. Antimicrobial resistance of Listeria monocytogenes isolates from food and the environment in France over a 10-year period. Appl Environ Microbiol 2011;77:2788-2790.

Henri C, Félix B, Guillier L, Leekitcharoenphon P, Michelon D, Mariet JF, Aarestrup FM, Mistou MY, Hendriksen RS, Roussel S. Population genetic structure of Listeria monocytogenes strains as determined by pulsed-field gel electrophoresis and multilocus sequence typing. Appl Environ Microbiol 2016;82:5720-5728.

Jamali H, Paydar M, Ismail S, Looi CY, Wong WF, Radmehr B, Abedini A. Prevalence, antimicrobial susceptibility and virulotyping of Listeria species and Listeria monocytogenes isolated from open-air fish markets. BMC Microbiol 2015;15: 144.

Jiang X, Yu T, Xu P, Xu X, Ji S, Gao W, Shi L. Role of efflux pumps in the in vitro development of ciprofloxacin resistance in Listeria monocytogenes. Front Microbiol 2018;9:2350.

Kehrenberg C, Schwarz S, Jacobsen L, Hansen LH, Vester B. A new mechanism for chloramphenicol, florfenicol and clindamycin resistance: Methylation of $23 \mathrm{~S}$ ribosomal RNA at A2503. Mol Microbiol 2005;57:1064-1073.

Kevenk TO, Gulel GT. Prevalence, antimicrobial resistance and serotype distribution of Listeria monocytogenes isolated from raw milk and dairy products. J Food Safety 2016;36:11-18.

Kovacevic J, Sagert J, Wozniak A, Gilmour MW, Allen KJ. Antimicrobial resistance and co-selection phenomenon in
Listeria spp. recovered from food and food production environments. Food Microbiol 2013;34:319-327.

Kulczycka-Mierzejewska K, Sadlej J, Trylska J. Molecular dynamics simulations suggest why the A2058G mutation in 23S RNA results in bacterial resistance against clindamycin. J Mol Model 2018;24:191.

Lampidis R, Kostrewa D, Hof H. Molecular characterization of the genes encoding DNA gyrase and topoisomerase IV of Listeria monocytogenes. J Antimicrob Chemother 2002;49: 917-924.

Li L, Olsen RH, Ye L, Wang W, Shi L, Yan H, Meng H. Characterization of antimicrobial resistance of Listeria monocytogenes strains isolated from a pork processing plant and its respective meat markets in Southern China. Foodborne Pathog Dis 2016;13:262268.

Lyon SA, Berrang ME, Fedorka-Cray PJ, Fletcher DL, Meinersmann RJ. Antimicrobial resistance of Listeria monocytogenes isolated from a poultry further processing plant. Foodborne Pathog Dis 2008;5:253-259.

Madeo M, Musumeci R, Careddu AM, Amato E, Pontello MM, Cocuzza CE. Antimicrobial susceptibility of Listeria monocytogenes isolates from human cases in northern Italy, 20082010: MIC determination according to EUCAST broth microdilution method. J Chemother 2015;27:201-206.

Magiorakos AP, Srinivasan A, Carey RB, Carmeli Y, Falagas ME, Giske CG, Harbarth S, Hindler JF, Kahlmeter G, OlssonLiljequist B, Paterson DL, Rice LB, Stelling J, Struelens MJ, Vatopoulos A, Weber JT, Monnet DL. Multidrug-resistant, extensively drug-resistant and pandrug-resistant bacteria: An international expert proposal for interim standard definitions for acquired resistance. Clin Microbiol Infect 2012;18:268281.

Moreno LZ, Paixão R, Gobbi DD, Raimundo DC, Ferreira TP, Moreno AM, Hofer E, Reis CM, Matté GR, Matté MH. Characterization of antibiotic resistance in Listeria spp. isolated from slaughterhouse environments, pork and human infections. J Infect Dev Ctries 2014;8:416-423.

Morvan A, Moubareck C, Leclercq A, Hervé-Bazin M, Bremont S, Lecuit M, Courvalin P, Le Monnier A. Antimicrobial resistance of Listeria monocytogenes strains isolated from humans in France. Antimicrob Agents Chemother 2010;54: 2728-2731.

Noll M, Kleta S, Al Dahouk S. Antibiotic susceptibility of 259 Listeria monocytogenes strains isolated from food, foodprocessing plants and human samples in Germany. J Infect Public Health 2017;11:572-577.

Poehlsgaard J, Pfister P, Böttger EC, Douthwaite S. Molecular mechanisms by which rRNA mutations confer resistance to clindamycin. Antimicrob Agents Chemother 2005;49:15531555 .

Pouillot R, Hoelzer K, Chen Y, Dennis SB. Listeria monocytogenes dose response evisited-incorporating adjustments for variability in strain virulence and host susceptibility. Risk Anal 2015;35:90-108.

Ragon M, Wirth T, Hollandt F, Lavenir R, Lecuit M, Le Monnier A, Brisse S. A new perspective on Listeria monocytogenes evolution. PLoS Pathog 2008;4:pii: e1000146.

Reichmann NT, Pinho MG. Role of SCCmec type in resistance to the synergistic activity of oxacillin and cefoxitin in MRSA. Sci Rep 2017;7:6154.

Rota C, Yanguela J, Blanco D, Carramiñana JJ, Ariño A, Herrera A. High prevalence of multiple resistance to antibiotics in 144 Listeria isolates from Spanish dairy and meat products. J Food Prot 1996;59:938-943. 
Ruiz-Bolivar Z, Neuque-Rico MC, Poutou-Piñales RA, Carrascal-Camacho AK, Mattar S. Antimicrobial susceptibility of Listeria monocytogenes food isolates from different cities in Colombia. Foodborne Pathog Dis 2011;8:913-919.

Safdar A, Armstrong D. Antimicrobial activities against 84 Listeria monocytogenes isolates from patients with systemic listeriosis at a comprehensive cancer center (1955-1997). J Clin Microbiol 2003;41:483-485.

Salcedo C, Arreaza L, Alcalá B, de la Fuente L, Vázquez JA. Development of a multilocus sequence typing method for analysis of Listeria monocytogenes clones. J Clin Microbiol 2003;41:757-762.

Scallan E, Hoekstra RM, Angulo FJ, Tauxe RV, Widdowson MA, Roy SL, Jones JL, Griffin PM. Foodborne illness acquired in the United States-major pathogens. Emerg Infect Dis 2011;17:7-15.

Schlech WF 3rd, Lavigne PM, Bortolussi RA, Allen AC, Haldane EV, Wort AJ, Hightower AW, Johnson SE, King SH, Nicholls ES, Broome CV. Epidemic listeriosis-evidence for transmission by food. N Engl J Med 1983;308:203-206.

Srinivasan V, Nam HM, Nguyen LT, Tamilselvam B, Murinda SE, Oliver SP. Prevalence of antimicrobial resistance genes in Listeria monocytogenes isolated from dairy farms. Foodborne Pathog Dis 2005;2:201-211.

Swaminathan B, Gerner-Smidt P. The epidemiology of human listeriosis. Microbes Infect 2007;9:1236-1243.

Teuber M. Spread of antibiotic resistance with food-borne pathogens. Cell Mol Life Sci 1999;56:755-763.

Thønnings S, Knudsen JD, Schønheyder HC, Søgaard M, Arpi M, Gradel KO, Østergaard C; Danish Collaborative Bacteraemia Network (DACOBAN). Antibiotic treatment and mortality in patients with Listeria monocytogenes meningitis or bacteraemia. Clin Microbiol Infect 2016;22:725-730.

Troxler R, von Graevenitz A, Funke G, Wiedemann B, Stock I. Natural antibiotic susceptibility of Listeria species: L. grayi, L. innocua, L. ivanovii, L. monocytogenes, $L$. seeligeri and $L$. welshimeri strains. Clin Microbiol Infect 2000;6:525-535.

Ueda F, Sugamata M, Aota M, Mochizuki M, Yamada F, Hondo R. Swift and definite serotyping for isolated Listeria monocytogenes strains. New Microbiol 2002;25:165-171.

Vela AI, Fernández-Garayzábal JF, Latre MV, Rodríguez AA, Domínguez L, Moreno MA. Antimicrobial susceptibility of
Listeria monocytogenes isolated from meningoencephalitis in sheep. Int J Antimicrob Agents 2001;17:215-220.

Walsh D, Duffy G, Sheridan JJ, Blair IS, McDowell DA. Antibiotic resistance among Listeria, including Listeria monocytogenes, in retail foods. J Appl Microbiol 2001;90:517522.

Wang XM, Lü XF, Yin L, Liu HF, Zhang WJ, Si W, Yu SY, Shao ML, Liu SG. Occurrence and antimicrobial susceptibility of Listeria monocytogenes isolates from retail raw foods. Food Control 2013;32:153-158.

Wieczorek K, Dmowska K, Osek J. Prevalence, characterization, and antimicrobial resistance of Listeria monocytogenes isolates from bovine hides and carcasses. Appl Environ Microbiol 2012;78:2043-2045.

Wilson A, Gray J, Chandry PS. Phenotypic and genotypic analysis of antimicrobial resistance among Listeria monocytogenes isolated from Australian food production chains. Genes 2018;9:pii: E80.

Yan H, Neogi SB, Mo Z, Guan W, Shen Z, Zhang S, Li L, Yamasaki S, Shi L, Zhong N. Prevalence and characterization of antimicrobial resistance of foodborne Listeria monocytogenes isolates in Hebei province of Northern China, 2005-2007. Int J Food Microbiol 2010;144:310-316.

Yan SF, Wang W, Bai L, Hu YJ, Dong YP, Xu J, Li FQ. Antimicrobial resistance, virulence profile, and molecular characterization of Listeria monocytogenes isolated from ready-to-eat food in China, 2013-2014. Biomed Environ Sci 2016;29:448-452.

Yücel N, Çitak S, Önder M. Prevalence and antibiotic resistance of Listeria species in meat products in Ankara, Turkey. Food Microbiol 2005;22:241-245.

Address correspondence to: Frédérique Pasquali, PhD

Department of Agricultural and Food Sciences Alma Mater Studiorum-University of Bologna

Via del Florio 2

Ozzano dell'Emilia 40064

Italy

E-mail: frederique.pasquali@unibo.it 